\title{
NUMERICAL STUDY OF BEHAVIOR OF SQUARE FOOTING ON GEOGRID-REINFORCED FLYASH BEDS UNDER STATIC LOADING
}

\author{
Bindiya $K^{1}$, S. Gangadhara ${ }^{2}$, H. C. Muddaraju ${ }^{3}$, Tejaswini B. $\mathbf{R}^{4}$ \\ ${ }^{1}$ Assistant Professor, Civil Engineering Department, JNNCE, Shivamogga, Karnataka, India \\ ${ }^{2}$ Associate Professor, Civil Engineering Department, UVCE, Bangalore, Karnataka, India \\ ${ }^{3}$ Assistant Professor, Civil Engineering Department, UVCE, Bangalore, Karnataka, India \\ ${ }^{4}$ Assistant Professor, Civil Engineering Department, SVCE, Bangalore, Karnataka, India
}

\begin{abstract}
The technique of ground improvement using geosynthetics has been developed extensively over the last few decades, in particular to those applied in pavement and foundation engineering. Fly ash is a naturally-cementations coal combustion by-product. Coal-based thermal power plants all over the world face serious problems of handling and disposal of the ash produced. Hence attempts are being made to utilize the ash rather than dump it. The main objective of this research study is to investigate the potential benefits of using the reinforced soil foundations to improve the load carrying capacity and reduce the settlement of shallow foundations on flyash. Numerical modelling is performed using PLAXIS version 8.2 which is finite element code for soil and rock analysis and is capable of modelling reinforced soils. A series of finite element analysis were performed to study the effectiveness of the reinforcement distribution (i.e, number of reinforcement layers and the spacing between the reinforcement layers) on the behaviour of the square footing on flyash beds. The dimensions of the tank used in analysis are $11 \mathrm{~m}$ diameter and $3.6 \mathrm{~m}$ height. The mild steel footing is used with the dimensions of $1 \mathrm{~m}$ width and $0.04 \mathrm{~m}$ thickness respectively. The loading condition used for the present study is Point load. The input values of point loads are given in force per unit width $(\mathrm{kN} / \mathrm{m})$. The static loads are applied up to $50 \mathrm{~mm}$ settlement. The analysis demonstrates that the reinforced flyash beds perform better than the unreinforced flyash beds. The performance of footing improves with increase in number of reinforcement layers. As the spacing between the reinforcement increases settlement will reduces.
\end{abstract}

Keywords: Reinforced fly ash beds, numerical modeling, PLAXIS, Point load.

\section{INTRODUCTION}

The technique of ground improvement using geosynthetics has been developed extensively over the last few decades, in particular to those applied in pavement and foundation engineering. The concept of reinforced soil as construction material is based on the existence of soil-reinforcement interaction due to tensile strength, frictional and the adhesion properties of the reinforcement and was first introduced by the French architect and engineer Henri Vidal in the 1960s. Since then, this technique has been widely used in geotechnical engineering practice.

Studies have shown that geogrid reinforced foundations can increase the ultimate bearing capacity and reduce the settlement of shallow footings, compared to the conventional methods, such as to replacing natural soils or increasing footing dimensions.(e.g. King et al. 1993; Mosallanezhad et al. 2010; Gill et al. 2011; Zidan 2012; Nagy et al. 2012; Gangadara et al. 2013)

Fly ash is a naturally-cementations coal combustion byproduct. Coal-based thermal power plants all over the world face serious problems of handling and disposal of the ash produced. Safe disposal of the ash without adversely affecting the environment and the large storage area required are major concerns. Hence attempts are being made to utilize the ash rather than dump it. This solves the problems associated with the disposal of fly ash. According to two dimensional finite element analysis on reinforced fly ash slope carried by Gill et al.(2011) fly ash can be used successfully as an embankment fill material.

Analyses have been made to obtain the behavior of square footing on geogrid-reinforced flyash beds under static loading. Most of the studies have been done on reinforced sand under both static and dynamic loads. Hence analysis is made to study the effectiveness of the reinforcement distribution (number of reinforcement layers and spacing between the reinforcement layers) on the behaviour of the square footing on flyash beds.

\section{NUMERICAL MODELING}

Numerical models in this study were made using the finite element program called PLAXIS version 8.2 which is finite element code for soil and rock analysis and is capable of 
modelling reinforced soils. The analysis is carried out by considering square shaped footing on flyash beds. In the analysis unreinforced and reinforced flyash beds are considered in order to check their effectiveness.

Plane strain model is used in the present case since footing are square in shape and in this model, deformation and stress state are assumed to be zero in $\mathrm{Z}$ directions. The 15 -node triangle is considered as very accurate element as it produces high quality stress results for difficult problems. Hence 15 node triangular elements were used for the analysis. The geometry model of specified dimensions i.e. a tank of $11 \mathrm{~m}$ diameter and $3.6 \mathrm{~m}$ height is created using Line option in the PLAXIS window. Figure 1 shows the Finite element mesh of geometry around footing with geogrid.

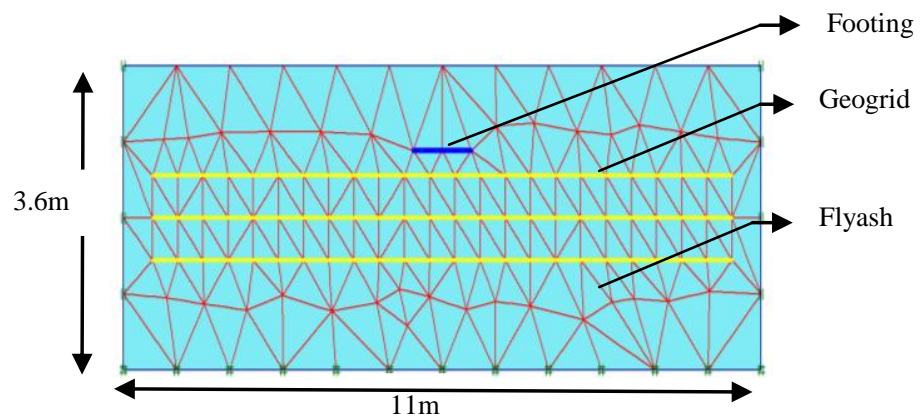

Fig -1: Finite element mesh.

The Mohr-Coulomb model is used for assigning flyash properties. The type of material used for footing is mild steel. Table 1 and Table 2 presents the properties of flyash and footing used in analysis. The biaxial geogrid are used as reinforcing material. The distance of geogrid is $10 \mathrm{~m}$ with $0.5 \mathrm{~m}$ clearence between tank and geogrid on both sides. The properties of geogrid used for analysis are shown in Table 3. Geogrids can be activated or de-activated in calculation phases using staged construction as loading input. The boundary condition used for present analysis is Standard fixities. PLAXIS contains the options to introduce distributed loads, line loads or point loads and prescribed displacements in the geometry model. The loading condition used for the present study is Point load. The input values of point loads are given in force per unit width $(\mathrm{kN} / \mathrm{m})$. The static loads are applied up to $50 \mathrm{~mm}$ settlement. Figure 2 shows the deformed mesh after analysis.

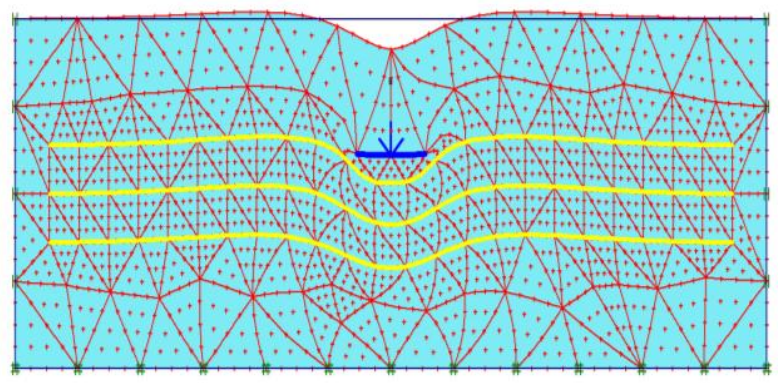

Fig -2: Deformed mesh after analysis.

Table 1: Properties of flyash

Table 2: Properties of footing

\begin{tabular}{|l|c|}
\hline \multicolumn{1}{|c|}{ PARAMETERS } & VALUES \\
\hline 1. Unsaturated Unit Weight & $14.37 \mathrm{kN} / \mathrm{m}^{3}$ \\
\hline 2. Saturated Unit Weight & $15.28 \mathrm{kN} / \mathrm{m}^{3}$ \\
\hline 3. Permeability & 0 \\
\hline 4. Reference Young's Modulus & $1202 \mathrm{kN} / \mathrm{m}^{2}$ \\
\hline 5. Poisson's Ratio & 0.2 \\
\hline 6. Cohesion & $40 \mathrm{kN} / \mathrm{m}^{2}$ \\
\hline 7. Friction Angle & $27^{\circ}$ \\
\hline 8. Dilatancy Angle & $0^{\circ}$ \\
\hline 9. Interface Strength & 0.8 \\
\hline
\end{tabular}

\begin{tabular}{|l|c|}
\hline \multicolumn{1}{|c|}{ PARAMETERS } & VALUES \\
\hline 1. Axial Stiffness (EA) & $8.4^{*} 10^{6} \mathrm{kN} / \mathrm{m}$ \\
\hline 2. Flexural Rigidity (EI) & $1120 \mathrm{kN}-\mathrm{m}^{2} / \mathrm{m}$ \\
\hline 3.Equivalent Plate Thickness & $0.04 \mathrm{~m}$ \\
\hline 4. Poisson's Ratio & 0.3 \\
\hline 5. Specific Weight & $3.14 \mathrm{kN} / \mathrm{m} / \mathrm{m}$ \\
\hline
\end{tabular}

Table 3: Properties of geogrids

\begin{tabular}{|c|c|}
\hline PARAMETERS & VALUES \\
\hline 1. Axial Stiffness (EA) & $14.38 * 10^{6} \mathrm{kN} / \mathrm{m}$ \\
\hline
\end{tabular}

\section{RESULTS AND DISCUSSION}

A series of finite element analysis were performed to study the effectiveness of the reinforcement distribution on the behaviour of the square footing on flyash beds. Zidan (2012) conducted a series of axi-symmetry models using finite element analyses (PLAXIS 2-DV8.2). The influence of geogrid becomes negligible when the ratio of depth of first layer to the footing diameter is equal to 0.5 . Hence a minimum spacing between the reinforcement layers is 0.3 times the width of footing is used in the analysis as this minimum thickness of the flyash bed is necessary for the reinforcement 
action. Also the first layer of reinforcement is placed at a minimum depth of 0.3times the width of footing, as this minimum thickness becomes essential for confinement effect.

\subsection{Effect of Number of Reinforcement Layers}

Figure 3, 4 and 5 presents the load v/s settlement curves for square footing resting on unreinforced and reinforced flyash beds with two, three and four layers of reinforcement at $\mathrm{S}=0.3 \mathrm{~B}, 0.4 \mathrm{~B}$ and $0.5 \mathrm{~B}$ respectively. It is observed from the figures that as the number of reinforcement layers increases the settlement reduces at any loading magnitude. For example, from the figure 3 , the footing on unreinforced flyash bed experiences a settlement of $31.15 \mathrm{~mm}$ at a loading magnitude of $50 \mathrm{kN} / \mathrm{m}$, whereas footing on reinforced flyash beds with two, three and four layers experiences the settlement of $19.54 \mathrm{~mm}, 18.94 \mathrm{~mm}$ and $16.5 \mathrm{~mm}$ at the same loading magnitude of $50 \mathrm{kN} / \mathrm{m}$ respectively. This indicates that the performance of reinforced flyash bed is better than unreinforced flyash bed. In reinforced flyash bed, as the number of reinforcement layers increases settlement will be less for the same loading compared to its counterparts.

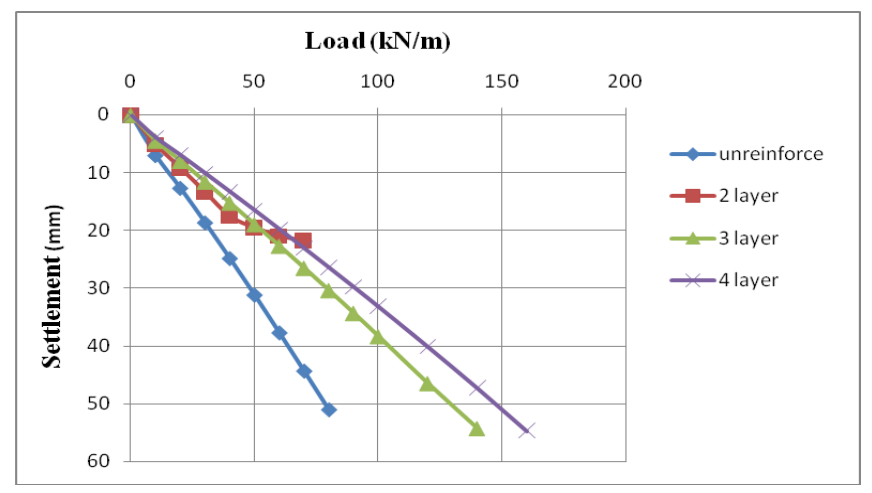

Fig- 3: Effect of number of reinforcement layers on the performance of square footing resting on flyash beds under static load and $\mathrm{S}=0.3 \mathrm{~B}$.

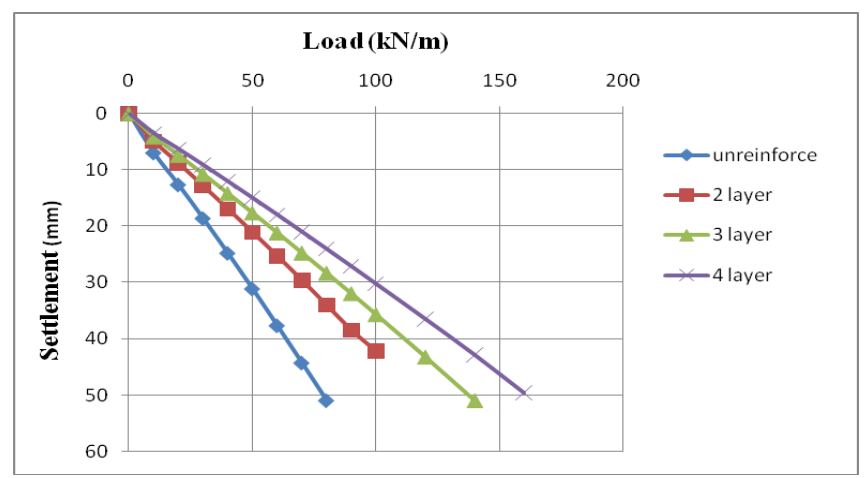

Fig- 4: Effect of number of reinforcement layers on the performance of square footing resting on flyash beds under a static load and $\mathrm{S}=0.4 \mathrm{~B}$.

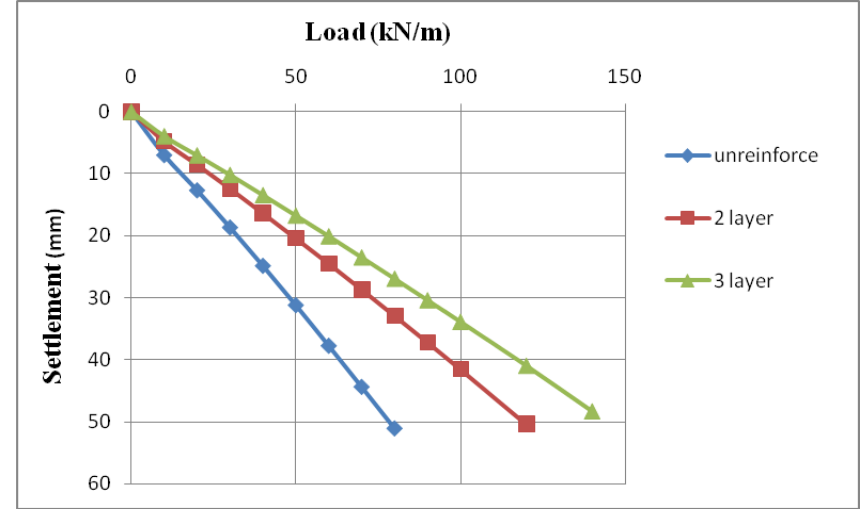

Fig- 5: Effect of number of reinforcement layers on the performance of square footing resting on flyash beds under a static load and $\mathrm{S}=0.5 \mathrm{~B}$.

\subsection{Effect of Reinforcement Spacing}

Figure 6, 7 and 8 presents the load v/s settlement curves for square footing resting on two, three and four layer reinforced flyash beds with spacing of $0.3 \mathrm{~B}, 0.4 \mathrm{~B}$ and $0.5 \mathrm{~B}$ respectively. It is observed from the figures that as the spacing between the reinforcement layers increases the settlement reduces at any loading magnitude. For example, from the figure 6 , the footing on flyash bed having reinforcement at $\mathrm{S}=0.5 \mathrm{~B}$ experiences a settlement of $16.41 \mathrm{~mm}$ at a loading magnitude of $40 \mathrm{kN} / \mathrm{m}$, whereas footing on flyash bed having reinforcement at $\mathrm{S}=0.4 \mathrm{~B}$ and $\mathrm{S}=0.3 \mathrm{~B}$ experiences the settlement of $16.94 \mathrm{~mm}$ and $17.57 \mathrm{~mm}$ at the same loading magnitude of $40 \mathrm{kN} / \mathrm{m}$ respectively. This indicates as the spacing between the reinforcement increases settlement will be less for same loading magnitude.

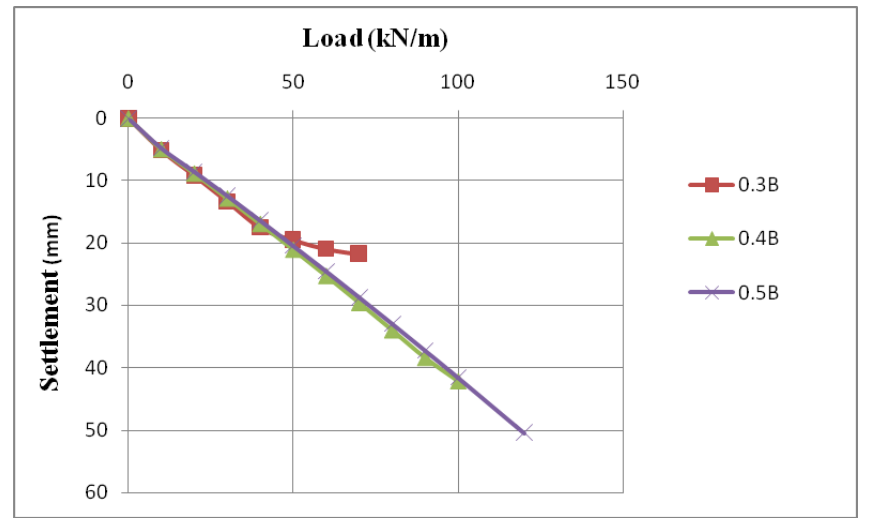

Fig- 6: Effect of reinforcement spacing on the performance of square footing resting on two layer reinforced flyash beds under a static load. 


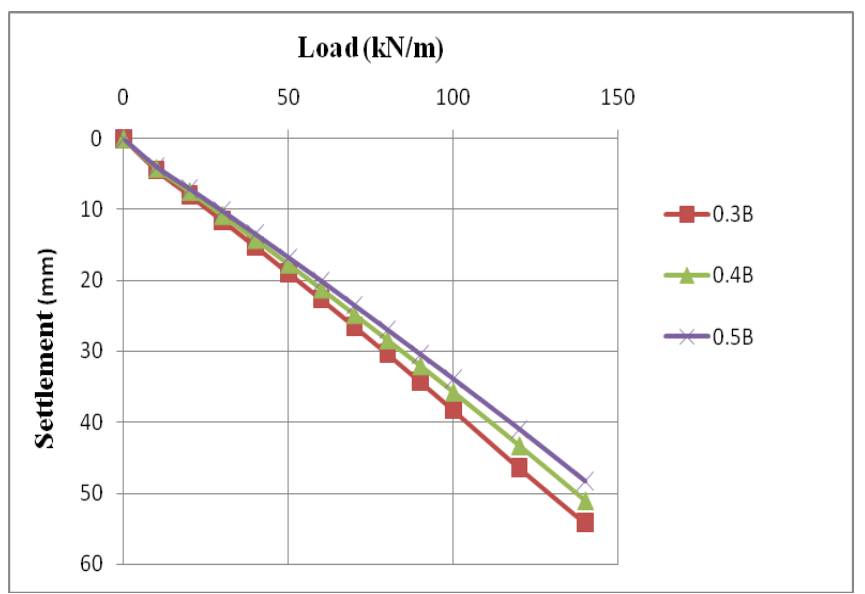

Fig- 7: Effect of reinforcement spacing on the performance of square footing resting on three layer reinforced flyash beds under a static load.

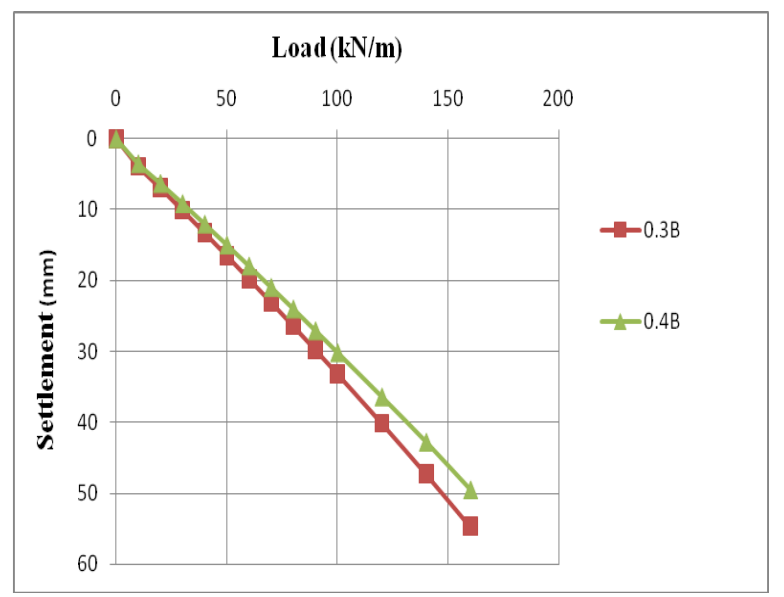

Fig- 8: Effect of reinforcement spacing on the performance of square footing resting on four layer reinforced flyash beds under a static load.

\section{CONCLUSIONS}

The following conclusions are drawn from the numerical analysis

1. Square footing resting on reinforced flyash bed perform better than its counterpart resting on unreinforced flyash beds.

2. As the number of reinforcement layer increases the performance of footing increases by taking more load and undergoing less settlement than its counterpart resting on reinforced flyash beds.

3. As the spacing between the reinforcement layer increases the performance of footing increases by taking more load and undergoing less settlement than its counterpart resting on reinforced flyash beds.

\section{REFERENCES}

[1]. Gangadara S. and Muddaraju H.C (2013) Effect of reinforcement Spacing on the Performance of Embedded Circular Footing in Reinforced Fly Ash, International Conference on Innovations In Civil Engineering.

[2]. Gill, K.S, Choudhary, A.K, Jha, J.N, and Shukla, S.K (2011) Load Bearing Capacity of Footing Resting on a Multilayer Reinforced Fly Ash Slope. Indian Geotechnical Conference 2011: pp. 4262-4271.

[3]. Khing, K.H., Das, B.M., Puri, V.K., Cook, E.E. and Yen, S.C. (1993) The bearing capacity of a strip foundation on geogrid-reinforced sand. Geotextiles and Geomembranes, 12(4), 351-361.

[4]. Mosallanezhad M, Hataf N. and Ghahramani A, 2010. Three Dimensional Bearing Capacity Analysis Of Granular Soil, Reinforced With Innovative GridAnchore System. Iranian Journal of Science and Technology 34:419-431.

[5]. Nagy A. El Mahallawy and Ahmad S. Rashed. (2012) Experimental Study for the Behaviour of Footings on Reinforced Sand Beds Overlying Soft Clay Zone, Journal of American Science, 8(1).

[6]. Plaxies Version 8.2,(2002) Materials models manual.

[7]. Zidan A. F. (2012) Numerical Study of Behavior of Circular Footing on Geogrid-Reinforced Sand Under Static and Dynamic Loading, Geotech Geol Eng 30:499-510.

\section{BIOGRAPHIES}

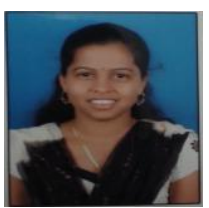

Assistant Professor in JNNCE, Shimoga. ME (Geo Technical Engineering), UVCE, Bangalore. BE (Civil Engineering), JNNCE, Shimoga

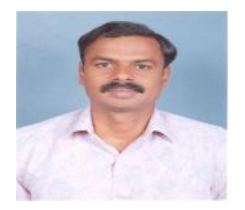

Associate Professor Dept of Civil Engineering UVCE, Bangalore University, Bangalore.56

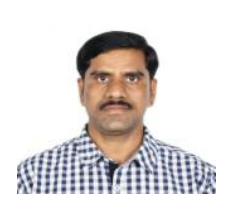

Assistant Professor Dept of Civil Engineering UVCE, Bangalore University,Bangalore.56,

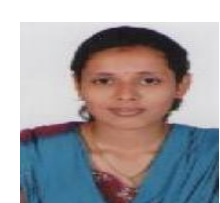

Assistant Professor in Sri Venkateshwara College of Engineering, Bangalore. ME (Geo Technical Engineering), UVCE, Bangalore. BE (Civil Engineering), Dr. AIT, Bangalore 